\title{
Investigation of the Teratogenic Potential of Ochratoxin A and B Using the FETAX System
}

\author{
E. O'Brien, ${ }^{*}$ A. Prietz, and Daniel R. Dietrich \\ Environmental Toxicology, University of Konstanz, Konstanz, Germany
}

\begin{abstract}
BACKGROUND: Ochratoxin A (OTA) is a mycotoxin produced by certain Aspergillus and Penicillium species. It has been observed to be teratogenic in a number of animal models including rat, mouse, hamster, and chick, with reduced birth weight and craniofacial abnormalities being the most commonly observed malformations. Neither the potential of OTA to cause malformations in humans nor its teratogenic mode of action is known. The FETAX system is an embryotoxicity assay system, with a high correlation to animal models and epidemiological data. Analysis of OTA-mediated teratogenesis using this system could provide a useful tool for the generation of high numbers of samples for mechanistic studies. METHODS: Using the standard ASTM 96-hr exposure protocol, the effect of OTA and its structural analogue OTB on the development of Xenopus laevis embryos in vitro was assessed. The accumulation of both substances in Xenopus embryos was also examined using tritiated OTA and OTB. RESULTS: Both OTA and OTB caused craniofacial malformations, while OTA also caused reduced embryo growth. As expected, OTA was far more potent in inducing these effects than OTB. This could at least in part be due to greater levels of OTA being accumulated within the embryos. CONCLUSIONS: The ability of FETAX to differentiate between close structural analogues indicates the assay has great potential for the elucidation of the embryotoxic and teratogenic mechanisms of action. Hence, the model could provide a suitable system for the investigation of other known teratogens or for the pre-screening of new agents for teratogenic potential.
\end{abstract}

Key words: ochratoxins; FETAX; teratogenesis; mycotoxins

\section{INTRODUCTION}

The mycotoxin ochratoxin A (OTA) is produced as a secondary metabolite by certain Aspergillus and Penicillium species (Scott et al., 1972). It is commonly found as a contaminant in animal feeds and human foodstuffs including cereals and cereal products, dried fruit, dried fish, coffee (Krogh, 1987; Studer-Rohr et al., 2000), meat and meat products, and in confectionary (DFG, 1990, 2000) with contamination levels ranging from $0.1-3.8 \mu \mathrm{g} /$ $\mathrm{kg}$ (Speijers and van Egmond, 1993; Studer-Rohr, 1995). Considerable levels of OTA have also been found in red wines at concentrations of up to $7 \mu \mathrm{g} / 1$. (Majerus and Otteneder, 1996; Viglione, 1998). The average human daily intake of OTA has been estimated at $1.2 \mathrm{ng} / \mathrm{kg}$ leading to plasma levels of approximately $0.5 \mathrm{ng} / \mathrm{ml}$, though it should also be noted that these levels may be considerably higher depending on individual and regional dietary habits (Studer-Rohr et al., 2000). Exposure to OTA has been demonstrated to be teratogenic in a number of species including rats (Brown et al., 1976), mice (Arora et al., 1983), hamsters (Hood et al., 1976), and chick (Wiger and Stormer, 1990). The most common defects noted are overt craniofacial abnormalities such as exencephaly, microphthalmia, facial clefts, and hypoplastic jaws, all of which appear to be dependent on both the dose and the period of gestation during which the toxin is administered (Wiger and Stormer, 1990). The timing of these effects coincides with the period of neurulation. Once the neuropores are closed, subsequent exposure has not been observed to be teratogenic. This may possibly be due to reduced placental transfer later in development (Appelgren and Arora, 1983; Fukui et al., 1987) or to a specific action of the toxin on the developing nervous system (Fukui et al., 1992; Szczech and Hood, 1981; Wei and Sulik, 1996).

OTA is a specific and potent animal teratogen and given the wide range of foodstuffs in which it is present it is hardly surprising that it has been detected in all human plasma samples to date (Kuiper-Goodman et al., 1993). Surprising if not disquieting, however, is that despite this and the fact that the half-life of OTA in humans is approximately $6-13$-fold longer than that

\footnotetext{
Abbreviations: ANOVA, analysis of variance; CCD, camera, computer controlled digital camera; DMSO, dimethyl sulphoxide; FETAX, frog embryo teratogenesis assay Xenopus: HCG, human chorionic gonadotropin; OTA, ochratoxin A; OTB, ochratoxin B; PMSG, pregnant mare's serum gonadotropin; SD, standard deviation.

*Correspondence to: Dr. Evelyn O'Brien, Environmental Toxicology, University of Konstanz, Jacob-Burckhardtstr. 25, P.O. Box X918, D-78457 Konstanz, Germany. E-mail: Evelyn.OBrien@Uni-Konstanz.de
} 
reported in rats (DFG, 1990; Li et al., 1997; Studer-Rohr et al., 2000) and that children and infants have been suggested to be more at risk from the toxic effects of OTA (Wolff et al., 2000), little or no research has been undertaken to identify possible risks to human foetal development. The molecular and cellular mechanism(s) by which these anomalies occur also remains to be elucidated. The overall effects of OTA exposure observed in vivo in rodent and in vitro using embryo culture models are similar to many malformations that have been described for humans for which the aetiology is unknown such as microcephaly, exencephaly, cleft lip, and cleft palate (CDC, 1998; Hood et al., 1976). Thus, this supports the requirement for a sequential analysis of the embryological and cellular evolution of OTAmediated malformations in a variety of model systems to provide more accurate information for human teratogenic risk assessment. Several short-term model systems such as the micromass test, whole embryo culture, and embryonic stem cells, currently exist; however, none of these has been validated for the identification of all classes of developmental toxicants (ECVAM, 2002; Piersma, 2004).

A further model system, which may fulfil many of the criteria for such mechanistic studies, is the frog embryo teratogenicity assay Xenopus (FETAX), which is currently being assessed by the Interagency Coordinating Committee on the Validation of Alternative Methods (ICCVAM). This assay provides a useful tool both for the analysis of such risks as well as for improved understanding of teratogenicity via mechanistic studies. The system incorporates all major stages and periods of sensitivity found in mammalian embryonic development (Bantle et al., 1988, 1991; Schoenwolf and Smith, 1990) without the involvement of exposure of the adult animals to the toxin. The FETAX assay has proven to be sensitive to the effects of other known human teratogens including thalidomide and retinoic acid (ASTM, 1991; Bantle et al., 1994; Dawson, 1991; Dumpert, 1986a,b) and has enabled the further elucidation of the mechanism of action of these agents. Using a range of substances, Sabourin and co-workers determined the system to have an overall predictive accuracy of $83 \%$ and a sensitivity of $85 \%$ with $15 \%$ false negatives (Sabourin and Faulk, 1987). A subsequent study carried out by the International Coordinating Committee on the Validation of Alternative Methods (Department of Health and Human Services), reported a predictive accuracy of $79 \%$, a sensitivity of $71 \%$, and a specificity of $92 \%$ (Panel, 2000). However, the system has not yet been validated as an alternative testing method and is subject to a considerable degree of inter-laboratory variation in both the reported results and in the endpoints recorded. A meeting of the Expert Panel on the frog embryo teratogenesis assay Xenopus made several recommendations for the further optimisation and validation of the assay including increasing the number of endpoints evaluated and the development of a reliable and accurate database for the identification of chemicals for which reliable FETAX data on mortality, malformation, and growth inhibition are available (Panel, 2000). In order to achieve this aim, a wider range of substances with demonstrated teratogenic potential (at least in rodent studies) must be evaluated using the FETAX assay. The use of closely related structural analogues with varying teratogenic potencies would also be invaluable in this respect.

Thus, the aim of this study was to characterise the teratogenic effects of OTA and its less potent structural analogue OTB, using the FETAX system. OTB differs from OTA only by the substitution of a chlorine molecule for a hydrogen molecule on the isocumarin moiety (Fig. 1). Comparison of the effects of these two structural analogues could provide valuable data for comparison with rodent studies and, moreover, a basis for future mechanistic studies.

\section{MATERIALS AND METHODS}

\section{Chemicals}

L-cysteine, HCG, and PMSG were purchased from Sigma Chemical Co. (Gillingham, UK). BTS-450 tissue solubiliser was obtained from Beckman Instruments (Fullerton, CA) and ${ }^{3} \mathrm{H}$-OTA $(1 \mathrm{mCi} / \mathrm{ml}$ in ethanol, purity $\geq 97 \%$, specific activity $6.66 \times 10^{11} \mathrm{~Bq} / \mathrm{mMol}$ ) was supplied by Moravek Biochemicals Inc. (Brea, CA). ${ }^{3} \mathrm{H}$-OTB $(1 \mathrm{mCi} / \mathrm{ml}$ in ethanol, purity $=99 \%$, specific activity $6.66 \times 10^{11} \mathrm{~Bq} / \mathrm{mMol}$ ) was custom-synthesised by tritium exchange with subsequent purification by TLC and HPLC by American Radiolabelled Chemicals Inc., St. Louis, MO. All other chemicals were of the highest grade commercially available. Highly purified OTA and OTB (purity $\geq 98 \%$, benzene free) were kindly provided by Dr. M. Stack, FDA, Washington, DC.

\section{Animals}

Adult South African clawed frog (Xenopus laevis) pairs were obtained from the animal research facility of the University of Konstanz and maintained in dechlorinated water at $24 \pm 1^{\circ} \mathrm{C}$, with a $14 \mathrm{hr} / 10 \mathrm{hr}$ light/dark cycle.

\section{FETAX Assay}

The FETAX assay was carried out essentially in accordance with the ASTM standard method (ASTM, 1991) except that ovulation and mating were induced by injection of 150 (males) or 250 (female) units PMSG into the dorsal lymph sac followed by 600 (male) and 700 units (female) HCG $48 \mathrm{hr}$ later. Embryos were de-jellied in $2 \% \mathrm{w} / \mathrm{v}$ L-cysteine, $\mathrm{pH} 8.1$, for $2 \mathrm{~min}$. Normally developing embryos between stages 8 and 11 were selected for exposure (Nieuwkoop and Faber, 1975) and maintained in groups of 25 individuals in $10 \mathrm{ml}$ FETAX medium (ASTM, 1991) to which the test substances were added to give the nominal concentrations indicated. Stock solutions of OTA and OTB were made up in $7 \%$

$$
\begin{array}{lll} 
& \text { R1 } & \text { R2 } \\
\text { Ochratoxin A : } & \text { Cl } & \text { H } \\
\text { Ochratoxin B : } & \text { H } & \text { H }
\end{array}
$$

Fig. 1. Molecular structures of OTA and OTB. Note that the only difference between the two compounds is the substitution of hydrogen for chlorine on the isocumarin moiety. 
sodium bicarbonate. Bicarbonate concentration never exceeded $0.1 \%$, which served as control in all experiments. Embryos were incubated at $24 \pm 1^{\circ} \mathrm{C}$, with a $14 \mathrm{hr}$ / $10 \mathrm{hr}$ light/dark cycle. Only assays meeting the criteria of the ATSM standard (mortality $\leq 10 \%$, malformation $\leq 7 \%$, positive $\mathrm{LC}_{50}$ and $\mathrm{EC}_{50}$ controls, data not shown) were included in the evaluation.

\section{${ }^{3} \mathrm{H}$-OTA and ${ }^{3} \mathrm{H}$-OTB Uptake Experiments}

Embryos were collected and selected as outlined above. ${ }^{3} \mathrm{H}$-OTA or ${ }^{3} \mathrm{H}$-OTB $(2 \mu \mathrm{Ci})$, were added to each exposure group. This concentration was selected as a concentration at which no teratogenic or developmental retardation effects had been observed in preliminary range-finding experiments (data not shown). Every $24 \mathrm{hr}$, dead embryos were removed and recorded and groups of embryos were initially rinsed in a 1,000-fold excess of cold OTA or OTB, followed by five washes in normal FETAX solution to completely remove surface-bound radioactivity. The embryos were solubilised in tissue solubiliser and submitted for liquid scintillation counting. Uptake was expressed as DPM per embryo \pm SD.

\section{Concentration-Response Effects}

For concentration-response experiments, nine concentrations of OTA and ten of OTB plus vehicle controls were used to generate reliable response curves for Probit analysis. Medium and test substances were renewed every $24 \mathrm{hr}$. Dead embryos were removed and recorded every $24 \mathrm{hr}$ and embryos remaining after $96 \mathrm{hr}$ were fixed in $70 \%$ ethanol and, in accordance with the recommendations of the expert panel meeting on the frog embryo teratogenesis assay Xenopus, individually assessed microscopically for developmental stage and malformations using standard criteria (Bantle et al., 1991; Nieuwkoop and Faber, 1975) within $48 \mathrm{hr}$ of fixation to avoid introduction of dehydration artefacts. Growth inhibition as measured by head-to-tail length was assessed using a CCD camera coupled to a custom-designed computer program (Visiometrics, Neser and Bubek GbR, Konstanz, Germany) and was expressed as percent control.

\section{Test Acceptability and Statistical Analysis}

All experiments were carried out three times in duplicate $(\mathrm{n}=3)$. Only tests with a control mortality $\leq 10 \%$ and malformation $\leq 7 \%$ were deemed acceptable for analysis.

Mortality and malformation data were analysed by Probit analysis and the resulting values subjected to ANOVA and Dunnett's post test. Results are expressed as the mean $\pm \mathrm{SD}$ and those significantly different from the control are indicated $\left({ }^{*} p<0.05,{ }^{* *} p<0.01\right)$. Uptake experiments were analysed using Bonferroni's multiple comparisons test. Results are expressed as the mean \pm SD and those significantly different from the control are indicated $\left({ }^{*} p<0.05,{ }^{* *} p<0.01\right)$.

\section{RESULTS \\ ${ }^{3}$ H-OTA and ${ }^{3}$ H-OTB Uptake}

Xenopus embryos appeared to maintain the level of ${ }^{3} \mathrm{H}$-OTA accumulated during the first $24 \mathrm{hr}$ up until the 72-hr timepoint. As the amount of ${ }^{3} \mathrm{H}$-OTA incorporated following 24-hr exposure was not significantly different to that at $72 \mathrm{hr}$, this suggests that uptake is not mediated by transdermal passive diffusion. However, ${ }^{3} \mathrm{H}$-OTA uptake increased considerably between 72 and $96 \mathrm{hr}$ (Fig. 2), which corresponds to the onset of mouth opening and the feeding reflex (Nieuwkoop and Faber, 1975). Thus, the oral uptake route appeared to supplement the initial route for OTA absorption. Uptake of ${ }^{3} \mathrm{H}$-OTB per embryo was consistently 3-7 times lower than that observed for ${ }^{3} \mathrm{H}$-OTA throughout the duration of the exposure and, similarly to OTA, a marked increase was observed in uptake following onset of the feeding reflex between 72 and $96 \mathrm{hr}$.

\section{Concentration/Response Curves}

Mortality. OTA was observed to cause a concentration-dependent increase in the rate of embryo mortality (Fig. 3a) with Probit analysis yielding an $\mathrm{LC}_{50}$ value of

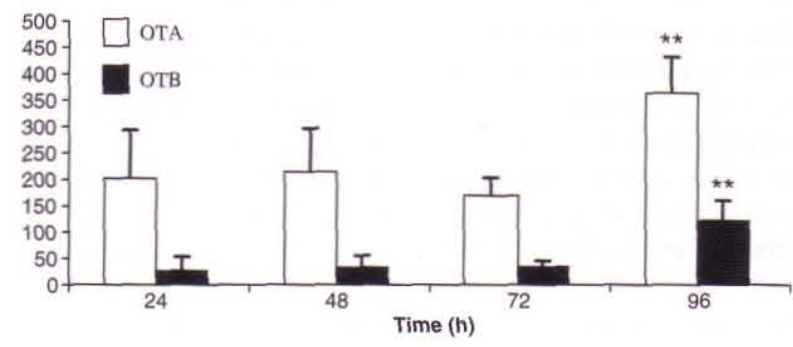

Fig. 2. Uptake of OTA and OTB into 24, 48, 72 and $96 \mathrm{~h}$ Xenopus laevis embryos. Embryos were incubated with $2 \mu \mathrm{Ci}$ OTA or OTB over 24-96h. Results are expressed as DPM/embryo (mean $\pm \mathrm{SD}$ ). A significant increase in the uptake of both substances was noted at the $96 \mathrm{~h}$ time-point $\left({ }^{* *} p \leq 0.01\right.$, Bonferroni's multiple comparison test).
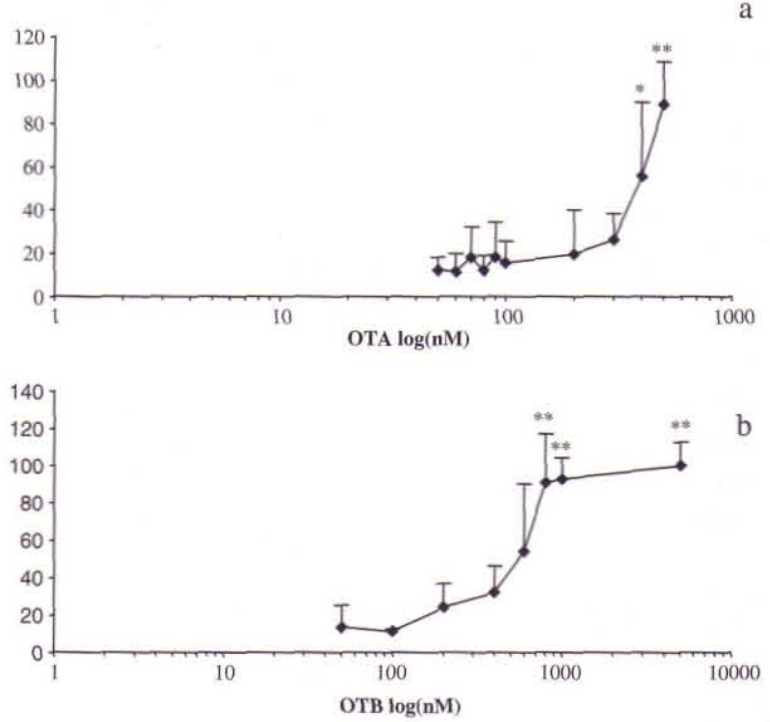

Fig. 3. Effect of OTA (a) and OTB (b) on embryo mortality following $96 \mathrm{~h}$ exposure. Results are expressed as percent mortality (mean \pm SD) and those significantly different from control are indicated $\left({ }^{*} p<0.05\right.$, ANOVA and Dunnett's post test). Note that OTA-mediated effects occur at concentrations approximately one order of magnitude lower than those of OTB. Values represent the mean $\pm \mathrm{SD}$. 
approximately $400 \pm 34.4 \mathrm{nM}$. Concentrations less than $200 \mathrm{nM}$ did not appear to have any consistent effect on survival. However, at values greater than $300 \mathrm{nM}$, the concentration-mortality curve was steep, with $88.7 \pm 19 \%$ mortality being achieved at $500 \mathrm{nM}$. In contrast to the results obtained for OTA, OTB concentrations greater than $400 \mathrm{nM}$ were necessary to induce mortality rates significantly different from control. OTB did however cause a concentration-dependent increase in embryo mortality rates (Fig. $3 \mathrm{~b}$ ) albeit at far greater concentrations than OTA, but also with a relatively steep concentration-response curve. Probit analysis revealed an $\mathrm{LC}_{50}$ value of $700 \pm 36.1 \mathrm{nM}$.

Malformation. OTA caused an increased incidence of a single specific and highly consistent malformation in Xenopus embryos (Fig. 4a). A distinct narrowing of the facial region and differences in overall facial shape were apparent. Probit analysis revealed an $\mathrm{EC}_{50}$ value of approximately $60 \pm 10.3 \mathrm{nM}$ for this malformation. At lower concentrations, the observed craniofacial abnormality was extremely subtle but increased dose-dependently in both incidence (Fig. 4a) and severity (Fig. 5a). This facial narrowing was not associated with an increase in the occurrence of any other malformations, e.g., retardation of gut coiling, and was, therefore, deemed to be a specific effect associated with OTA exposure rather than a generalised retardation of development (Bantle et al., 1991). Similarly to OTA, a concentrationdependent increase in the number of malformed embryos was recorded following OTB exposure (Fig. 4b). These embryos also displayed craniofacial narrowing similar to that observed following exposure

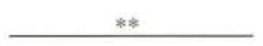

a
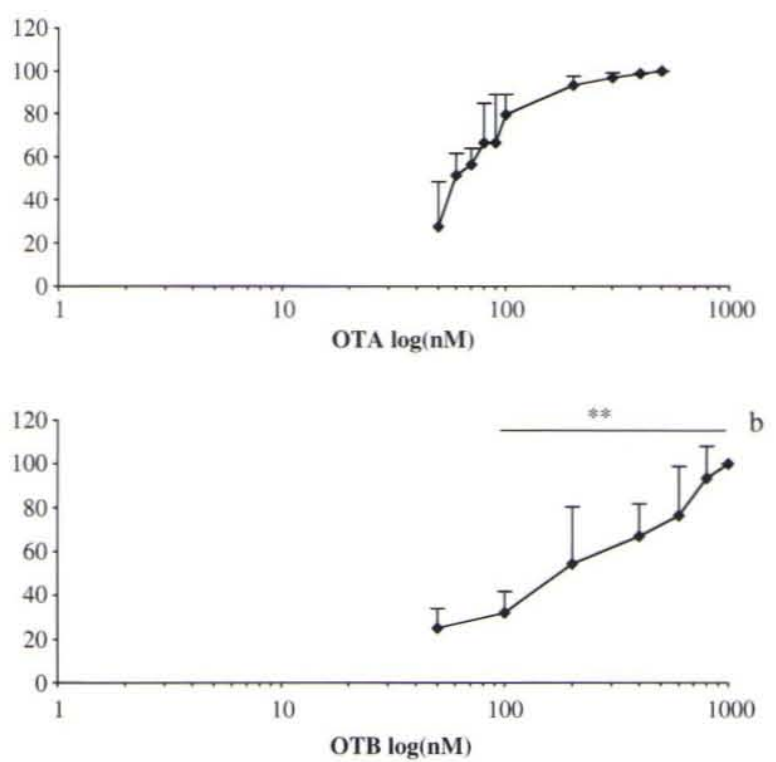

Fig. 4. Concentration-dependent induction of malformations in Xenopus laevis embryos following $96 \mathrm{~h}$ exposure to OTA (a) and OTB (b). Malformation was assessed according to standard ASTM criteria and are expressed as percentage malformed embryos (mean \pm SD) and those significantly different from control are indicated $\left({ }^{*} p<0.05\right.$, ANOVA and Dunnett's post test). Note that OTA-mediated effects occur at concentrations annroximately nne order of maonitude lower than those of OTR to OTA (Fig. 5b); however, far higher concentrations $\left(\mathrm{EC}_{50}=200 \pm 26.2 \mathrm{nM}\right)$ were required to produce these effects. In contrast to the situation with OTA, this craniofacial narrowing was also associated with a trend toward retarded gut coiling, which, however, only became statistically significant at the extremely high concentration of $600 \pm 34.04 \mathrm{nM}$ (data not shown).

Growth Inhibition. Embryos exposed to higher concentrations $(>200 \mathrm{nM})$ of OTA were observed to be significantly growth inhibited. On average, embryos exposed to $400 \mathrm{nM}$ were $10 \%$ shorter than controls (Fig. 6a) with some individual animals being up to $20 \%$ shorter. This effect did not appear to be a generalised retardation of development as gut coiling, an early marker of such effects, was complete at $96 \mathrm{hr}$ even in embryos exposed to $400 \mathrm{nM}$ OTA (data not shown). Although OTB-exposed embryos displayed a slight tendency toward growth inhibition as assessed by length measurement, this effect was not statistically significant even at the highest concentration $(1 \mu \mathrm{M})$ tested (Fig. $6 \mathrm{~b}$ ).

\section{DISCUSSION}

The nephrotoxic effects of ochratoxins have received greater attention than their potential teratogenic effects (O'Brien and Dietrich, 2005a,b), possibly due to the inherent difficulties associated with in vivo teratogenicity studies (species specificity, sensitivity window, cost
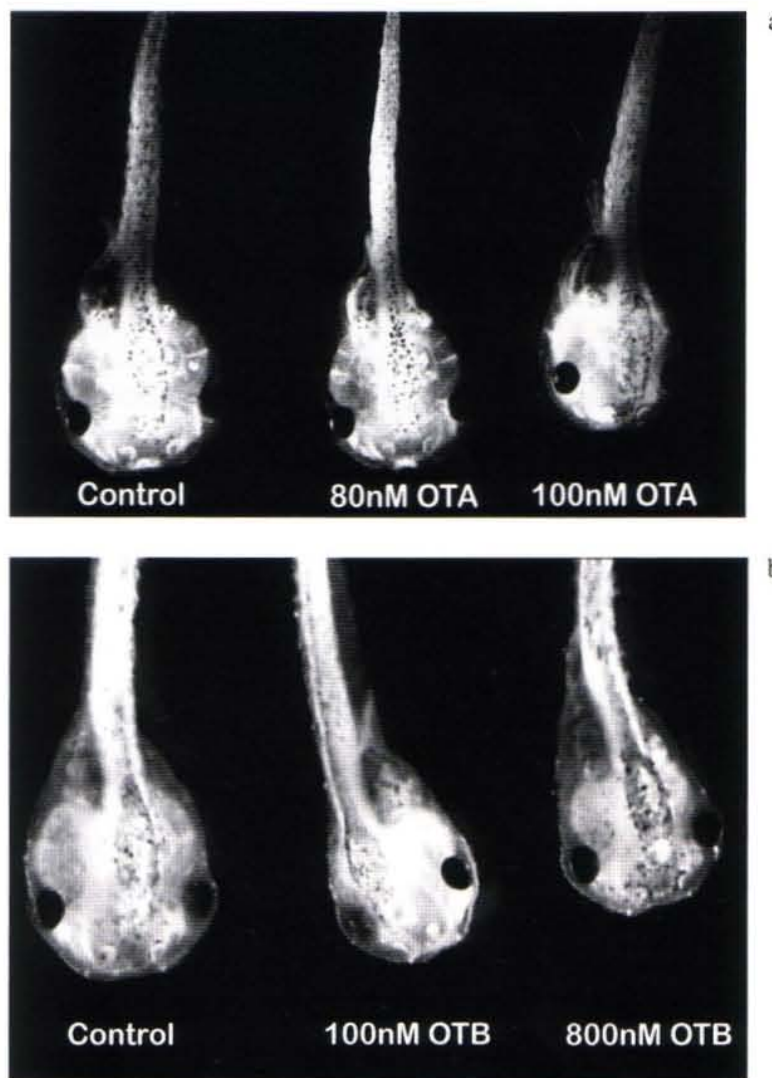

Fig. 5. Craniofacial narrowing caused by exposure to OTA (a) and OTB (b). Control embryos displayed the normal, slightly rounded shape, whereas ochratoxin exposure resulted in the develonment of a moro V/chaned form 

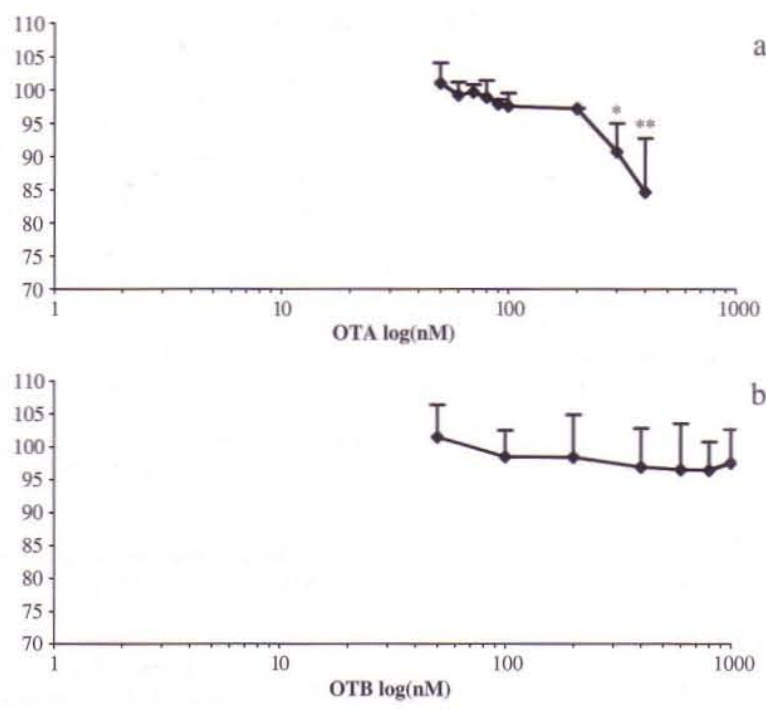

Fig. 6. Effects of OTA (a) and ОTВ (b) on embryo growth. Results are expressed as percentage control (mean \pm SD) and those significantly different from control are indicated $\left({ }^{*} p<0.05\right.$, ANOVA and Dunnett's post test).

of pure toxin). Thus, the mechanism(s) of OTA-induced teratogenesis remain unclear. The FETAX assay is a relatively simple and rapid method for generating large amounts of analytical data. This assay system allows for very specific interventions during embryogenesis and could, therefore, prove useful for mechanistic studies. Therefore, the aims of this study were to investigate if the previously reported teratogenic effects observed in rodent models could be reproduced using Xenopus laevis embryos and to determine if the observed effects are specific in nature or as a result of general embryo toxicity. Furthermore, the investigation aimed to provide initial information on the previously observed differences in the teratogenic potentials of OTA and its structural analogue, OTB. This was achieved by assessing several standard FETAX parameters including mortality, malformation, and embryo growth.

The comparison of the concentration-mortality curves for the two analogues reveals differences in the toxic effects with higher concentrations of OTB being necessary to cause a significant increase in embryo mortality. OTA displays the classic characteristics of a teratogen in that a high degree of malformation is apparent before significant effects on mortality can be detected. In contrast, for OTB the effects of mortality, craniofacial narrowing, and retarded gut coiling appear to coincide with each other, thus suggesting OTB to be embryotoxic rather than teratogenic. It should, however, be reiterated that these effects only occurred at extremely high concentrations. In this study, both ochratoxin A and ochratoxin B were observed to specifically cause craniofacial narrowing in Xenopus laevis embryos in a concentration-dependent manner. The previously reported relative toxicity differences between OTA and OTB were also apparent with approximately four-fold higher concentrations of OTB being required to achieve a similar malformation rate and grade (Wiger and Stormer, 1990). The predominant effects in rodents following in utero exposure to OTA in these models were also most evident in the craniofacial regions. In mice, alongside an increased incidence of resorption, the most commonly noted defects are exencephaly, neurocranial defects, neural tube and thoracic malformations, narrowing of the craniofacial skeleton, and a decrease in foetal size (Arora and Frolen, 1981; Wei and Sulik, 1993). Dosing of pregnant rats p.o. with $0.75-1 \mathrm{mg} / \mathrm{kg}$ OTA resulted in an increased incidence of embryo resorption, but also in decreased foetal size and increased skeletal defects, primarily in the craniofacial region (Mayura et al., 1982, 1984).

In rats, these effects have been attributed to a specific action of ochratoxin itself and not as a result of maternal toxicity or maternal production of OTA metabolites, as OTA has been found at relatively high concentrations $(64.2 \mathrm{ng} / \mathrm{g})$ in rat foetal tissue following single maternal dosing with $2.5 \mathrm{mg} / \mathrm{kg}$ s.c., without detection of metabolic congeners (Ballinger et al., 1986). In contrast, pigs are insensitive to the teratogenic effects of OTA, probably due to the lack of placental transfer (Mortensen et al., 1983; Shreeve et al., 1977).

The concentrations of OTA necessary to induce malformations in FETAX embryos were far lower than those employed in earlier rodent studies. This is most likely due to the faster rate of amphibian embryonic development leading to an inherent higher susceptibility to toxic insult, particularly with respect to substances, which mediate their toxic effects by disruption of the cell cycle. In support of this hypothesis, preliminary data from our laboratory indicate OTA to arrest primary human and primary porcine renal epithelial cells as well as the NRK-52E (rat) and LLC-PK1 (pig) continual cell lines in the G2 phase of the cell cycle (Dreger et al., 2000; Wolf et al., 2002).

The OTA-mediated decrease in average embryo length noted in this study, appears to correspond to the decrease in embryo size and birth weight noted by other authors (Arora and Frolen, 1981; Mayura et al., 1984; Mayura et al., 1982; Wei and Sulik, 1993). OTB, in contrast had no significant effect on embryo growth. This corresponds to its lesser toxic potential.

The observed differences in the toxicities of OTA and OTB remain to be explained. One possibility is differences in the amount of OTA gaining access to the embryos. In this study, we measured OTA and OTB uptake into FETAX embryos throughout the $96 \mathrm{~h}$ duration of the test. OTA uptake was consistently 3-7-times higher than that of OTB. The measurements made here are unlikely to be due to degradation of the tritiated compounds to yield tritiated water. Studer-Rohr and co-authors, using the same source and specific activity of ${ }^{3}$ H-OTA have previously determined the degradation rate of ${ }^{3} \mathrm{H}$-OTA generated by tritium exchange, to be less than $2 \%$ over 21 days at $37^{\circ} \mathrm{C}$ (Studer-Rohr et al., 2000). Thus, it is unlikely that significant degeneration occurred over 96 hours at $24^{\circ} \mathrm{C}$. Furthermore, if these observations were due to the presence of significant amounts of tritiated water, then the values obtained for OTA and OTB uptake should not display the large differences observed.

The uptake patterns for ochratoxins observed in this study do not indicate transdermal incorporation via a passive diffusion mechanism, as uptake was observed to be independent of both embryo size and surface area. Indeed recent investigations into the transport of 
ochratoxins have indicated them to be subject to transport via specific organic anion transporters (Babu et al., 2002; Jung et al., 2001; Tsuda et al., 1999). It is possible that these transporters, which are known to transport organic anions both in and outwards may be able to maintain a balance during the initial phases of embryonic development and that this mechanism is overloaded following the onset of the feeding reflex, resulting in an increase in uptake. Further investigations using transporter expression systems should shed light on the kinetics and dymanics of OTA uptake.

The difference in OTB and OTA incorporation levels and/or transport kinetics could at least in part account for the differences in the toxic potentials of the two substances. Such differences in incorporation could also arise due to variations in their ability to bind to embryonic proteins. Initial results obtained in our laboratory using rodent, porcine and human renal homogenates do indeed indicate differences in the binding characteristics of the two toxins (Heussner et al., 2002), however no information is currently available on ochratoxin-protein binding in amphibians.

In summary, the effects of ochratoxin exposure in the FETAX system are similar to those observed in previous in vivo models, however, the assay offers several advantages over standard testing methods: firstly, it does not involve exposure of the mother animal, results can be obtained more rapidly and finally, large numbers of samples can be generated for biochemical, histological and molecular biological investigations. Recent studies aimed at assessing the use of Xenopus tropicalis in a similar testing system have yielded promising results (Fort et al., 2004; Song et al., 2003). X. tropicalis responded to known teratogens and substances previously tested positive in the standard FETAX system in a similar manner to $X$. laevis, with some differences in the teratogenic index (TI), however, use of the TI is only recommended if the slopes of the mortality and malformation concentration-response curves are parallel (Panel, 2000). These differences are probably due to the differing optimum temperatures between the two species. This member of the Xenopus family presents distinct advantages over the current $X$. laevis system, including a shorter generation time, allowing testing of effects over several generations and a diploid rather than tetraploid genome, making the system more amenable to the generation of knock-out strains and analysis using gene chip expression analysis (Panel, 2000). Concerns about the susceptibility of these animals to disease remain however and extensive testing of further substances must also be carried out to accurately assess the potential of this species for teratogenicity testing. Thus, despite certain justified reservations with respect to the use of an amphibian test system for the assessment of embryotoxicity, the results of the current study indicate the potential of the FETAX system for the investigation of the mechanism of OTA-induced teratogenicity.

\section{ACKNOWLEDGMENTS}

We express our gratitude to the Alexander von Humboldt Stiftung for a fellowship for Evelyn O'Brien and Dr. M.E. Stack, FDA, Washington for providing highly purified OTA and OTB.

\section{REFERENCES}

Appelgren L-E, Arora RG. 1983. Distribution of ${ }^{14} \mathrm{C}$-labelled ochratoxin A in pregnant mice. Fundament Chem Toxicol 21:563-568.

Arora RG, Froelein H, Fellner-Feldegg H. 1983. Inhibition of ochratoxin A teratogenesis by zearalenone and diethylstilboestrol. Fundament Chem Toxicol 21:779-783.

Arora RG, Frolen H. 1981. Interference of mycotoxins with prenatal development of the mouse. II. Ochratoxin A induced teratogenic effects in relation to the dose and stage of gestation. Acta Vet Scand 22:535-552.

ASTM. 1991. Standard guide for conducting the frog embryo teratogenesis assay, Xenopus (Fetax). E 1439-91. Annual Book of ASTM Standards. Philadelphia: American Society for Testing and Materials. p 1-11.

Babu E, Takeda M, Narikawa S, Kobayashi Y, Enomoto A, Tojo A, Cha SH, Sekine T, Sakthisekaran D, Endou H. 2002. Role of human anion transporter 4 in the transport of ochratoxin A. Biochim Biophys Acta 1590:64-75.

Ballinger MB, Phillips TD, Kubena LF. 1986. Assessment of the distribution and elimination of ochratoxin $A$ in the pregnant rat. J Food Safety 8:11-24.

Bantle JA, Burton DT, Dawson DA, Dumont JN, Finch RA, Fort DJ, Linder G, Rayburn JR, Buchwalter D, Gaudet-Hull AM, Maurice MA, Turley SD. 1994. FETAX interlaboratory validation study: Phase II testing. Environ Toxicol Chem 13:1629-1637.

Bantle JA, Dumont JN, Finch R, Linder G. 1991. Atlas of abnormalities: A Guide for the Performance of FETAX. Stillwater, OK: Oklahoma State Publications Department. 69 p.

Bantle JA, Fort DJ, Dawson DA. 1988. Bridging the gap from short-term teratogenesis assays to human health hazard assessment by understanding common modes of teratogenic action. In: Cowgill UM, Williams LR, editors. Aquatic toxicology and hazard assessment. p 46-57.

Brown MH, Szczech GM, Purmalis BP. 1976. Teratogenic and toxic effects of ochratoxin A in rats. Toxicol Appl Pharmacol 37:331-338.

CDC. 1998. Centers for birth defects: research and prevention. Atlanta: US department of health and human services. Report No. CDC-NCEH 98-0310.

Dawson DA. 1991. Joint action of t-retinoic and valproic acids on Xenopus embryo development. Teratogenesis, Carcinogen Mutagen 11:317-325.

Department of Health and Human Services NIoH, ICCVAM Special Emphasis Panel. Xenopus (FETAX). 2000. A proposed screening method for identifying the developmental toxicity potential of chemicals and environmental samples. North Carolina, USA.

DFG. 1990. Ochratoxin A, Vorkommen und toxikologische Bewertung. Bonn: Deutsche Forschungsgemeinschaft.

DFG. 2000. Belastung des Verbrauchers und der Lebensmittel mit Ochratoxin A. Bonn: Deutsche Forschungsgemeinschaft.

Dreger S, O'Brien E, Stack M, Dietrich D. 2000. Antiproliferative effects and cell-cycle specific effects of ochratoxin A in LLC-PK1, NRK-52E and porcine primary proximal kidney cells. Toxicol Sci 54:170.

Dumpert K. 1986a. Embryotoxic effects of environmental chemicals: Tests with the South African clawed toad (Xenopus laevis). Ecotoxicol Environ Safety 13:324-338.

Dumpert K. 1986b. Tests with the South African clawed toad (Xenopus laevis) for detecting chemical causes of the decrease of amphibians. Chemosphere 15:807-811.

ECVAM. 2002. The micromass test: method of Brown. http://ecvamsis. jrc.it/IP1685/published/indexed_122.html

Fort DJ, Rogers RL, Thomas JH, Buzzard BO, Noll AM, Spaulding CD. 2004. Comparative sensitivity of Xenopus tropicalis and Xenopus laevis as test species for the FETAX model. J Appl Toxicol 24:443-457.

Fukui Y, Hayasaka S, Itoh M, Takeuchi Y. 1992. Development of neurons and synapses in ochratoxin A-induced microcephalic mice: a quantitative assessment of somatosensory cortex. Neurotoxicol Teratol 14:191-196.

Fukui Y, Hoshino K, Kameyama Y, Yasui T, Toda C, Nagano H. 1987. Placental transfer of ochratoxin $\mathrm{A}$ and its cytotoxic effect on the mouse embryonic brain. Food Chem Toxicol 25:17-24.

Heussner AH, O'Brien E, Dietrich DR. 2002. Species- and sex-specific variations in binding of ochratoxin $A$ by renal proteins in vitro. Exp Toxicol Pathol 54:151-159.

Hood RD, Naughton MJ, Hays AW. 1976. Prenatal effects of ochratoxin A in hamsters. Teratology 13:11-14.

Jung KY, Takeda M, Kim DK, Tojo A, Narikawa S, Yoo BS, Hosoyamada M, Cha SH, Sekine T, Endou H. 2001. Characterization of ochratoxin A transport by human organic anion transporters. Life Sci 69:2123-2135.

Krogh P. 1987. Ochratoxins in food. In: Krogh P, editor. Mycotoxins in food. London: Harcourt Brace Jovanovich. p 97-121. 
Kuiper-Goodman T, Ominski K, Marquardt RR, Malcolm S, McMullen E, Lombaert GA, Morton T. 1993. Estimating human exposure to ochratoxin $\mathrm{A}$ in Canada. Human ochratoxicosis and its pathologies. Montrouge, France: John Libbey Eurotext Ltd. p 167-174.

Li S, Marquardt RR, Frohlich AA, Vitti TG, Crow G. 1997. Pharmacokinetics of ochratoxin A and its metabolites in rats. Toxicol Appl Pharmacol 145:82-90.

Majerus P, Otteneder H. 1996. Nachweis und vorkommen on Ochratoxin $A$ in Wein und Traubensaft. Deutsche Lebensmittel-Rundschau 92: 388-390.

Mayura K, Parker R, Berndt WO, Phillips TD. 1984. Ochratoxin A - induced teratogenesis in rats: Partial protection by phenylalanine. Appl Environ Microbiol 48:1186-1188.

Mayura K, Reddy RV, Hayes AW, Berndt WO. 1982. Embryocidal, fetotoxic and teratogenic effects of ochratoxin A in rats. Teratology 25:175-185.

Mortensen HP, Hald B, Madsen A. 1983. Feeding experiments with ochratoxin A contaminated barley for bacon pigs: 5. Ochratoxin A in pig blood. Acta Agricult Scand 33:235-239.

Nieuwkoop PD, Faber J. 1975. Normal table of Xenopus laevis (Daudin): A systematical and chronological survey of the developmental stages from the fertilized egg till the end of metamorphosis, 2nd ed. Amsterdam: North-Holland Publishing Company. 252 p.

O'Brien E, Dietrich DR. 2005a. Mycotoxins affecting the kidney. In: Tarlof JB, Lash LH, editors. Toxicology of the kidney, 3rd ed. Boca Raton, FL: CRC Press.

O'Brien E, Dietrich DR. 2005b. Ochratoxin A: The continuing enigma. Crit Rev Toxicol 35:33-60.

Panel 2000. Minutes of the expert panel meeting on the frog embryo teratogenesis assay- Xenopus (FETAX): a proposed screening method for identifying the developmental toxicity potential of chemicals and environmental samples. Durham, NC: DHHS, NIH, NIEHS, ICCVAM. 1-20 p.

Piersma AH. 2004. Validation of alternative methods for developmental toxicity testing. Toxicol Lett (Amsterdam) 149:147-153.

Sabourin TD, Faulk RT. 1987. Comparative evaluation of a short-term test for developmental effects using frog embryos. In: McLachlan JA, Pratt RM, Markert CL, editors. Banbury Report 26: Developmental toxicology: mechanisms and risk. Cold Spring Harbor, NY: Cold Spring Harbor Laboratory. p 203-223.

Schoenwolf GC, Smith, J.L. 1990. Mechanisms of neurulation: traditional viewpoint and recent advances. Development 109:243-270.

Scott PM, Van Walbeck W, Kennedy B, Anyeti D. 1972. Mycotoxins (ochratoxin A, citrinin and sterigmatocystin) and toxigenic fungi in grains and agricultural products. J Agricult Food Chem 20: 1103-1109.

Shreeve BJ, Patterson DS, Pepin GA, Roberts BA, Wrathall AE. 1977. Effect of feeding ochratoxin to pigs during early pregnancy. Br Vet J 133:412-417.

Song MO, Fort DJ, McLaughlin DL, Rogers RL, Thomas JH, Buzzard BO, Noll AM, Myers NK. 2003. Evaluation of Xenopus tropicalis as an alternative test organism for frog embryo teratogenesis assay Xenopus (FETAX). Drug Chem Toxicol 26:177-189.

Speijers GJA, van Egmond HP. 1993. Worldwide ochratoxin A levels in food and feeds. Human ochratoxicosis and its pathologies. Montrouge, France: John Libbey Eurotext Ltd. p 85-100.

Stratford MLR, Watfa RR, Clifford MJ, Martin SG. 1990. Determination of Collagen and Protein Turnover by high-performance liquid chromatograghy. J Chromatogr 526:383-395.

Studer-Rohr I. 1995. Ochratoxin A in humans: exposure, kinetics and risk assessment. Zürich: Swiss Federal Institute of Technology Zürich. $100 \mathrm{p}$.

Studer-Rohr J, Schlatter J, Schlatter C, Dietrich DR. 2000. Intraindividual variation in plasma levels and kinetic parameters of ochratoxin $\mathrm{A}$ in humans. Arch Toxicol 74:499-510.

Szczech GM, Hood RD. 1981. Brain necrosis in mous fetuses transplacentally exposed to the mycotoxin ochratoxin A. Toxicol Appl Pharmacol 57:127-137.

Tsuda M, Sekine T, Takeda M, Cha SH, Kanai Y, Kimura M, Endou H. 1999. Transport of ochratoxin A by renal multispecific organic anion transporter 1. J Pharmacol Exp Therapeut 289:1301-1305.

Viglione P. 1998 5.12.1998. Contamination of red wine with ochratoxin A [Elintarvikevirasto jyräsi salailevan Alkon]. Ilta-Sanomat; A8-A9.

Wei X, Sulik KK. 1993. Pathogenesis of craniofacial and body wall malformations induced by ochratoxin A in mice. Am J Med Genet $47: 862-871$

Wei X, Sulik KK. 1996. Pathogenesis of caudal dysgenesis/sirenomelia induced by ochratoxin A in chick embryos. Teratology 53:378-391.

Wiger R, Stormer FC. 1990. Effects of ochratoxins A and B on prechondrogenic mesenchymal cells from chick embryo limb buds. Toxicol Lett 54:129-134.

Wolf P, O'Brien E, Heussner AH, Stack ME, Thiel R, Dietrich DR. 2002. Sex- and age-specific effects of ochratoxin $\mathrm{A}$ in primary human kidney cells (HKC). Toxicol Sci 66:400.

Wolff J, Bresch H, Cholmakow-Bodechtel C, Engel G, Erhardt S, Gareis M, Majerus P, Rosner H, Scheuer R. 2000. Belastung des Verbrauchers und der Lebensmittel mit Ochratoxin A. forschungsverbund Produkt- und Ernährungsforschung des Bundesministeriums für Ernährung, Landwirtschaft und Forsten. 243 p. 